\title{
Reducing diffuse water pollution by tailoring incentives to region specific requirements: empirical study for the Burdekin River basin (Australia)
}

\author{
R. Greiner \& O. Miller \\ River Consulting, Townsville, Queensland, Australia
}

\begin{abstract}
Australia is facing many environmental problems caused by agricultural diffuse pollution. Policies and programmes are being developed for landholders to improve environmental performance. One tool for achieving environmental improvements is the design and promotion of 'best management practices' (BMPs). These are conservation practices aimed at reducing diffuse pollution from agricultural lands and thus improving end-of-catchment water quality. A suite of grazing region-specific BMPs were developed for the Burdekin Dry Tropics region in north-eastern Australia. While they were developed in a consultative fashion, there was no explicit consideration of knowledge of adoption processes or supporting incentives. This paper utilises the data from an earlier grazier survey to explore what extent landholder motivations influence the adoption of BMPs and to gauge landholder preferences for incentives. The results highlight critical correlations between landholder goals, barriers to adoption of conservation practices, and preferred incentives to help overcome barriers. We conclude that a sound understanding is required not only of regional environmental issues but also the people and business situations which control diffuse pollution so as to tailor programmes aimed at improving regional environmental performance.
\end{abstract}

Keywords: diffuse pollution, non-point pollution, water quality, conservation practices, incentives, adoption, grazing, Burdekin River basin, Great Barrier Reef, empirical research, correlations, factor analysis. 


\section{Introduction}

Agricultural land use generates or contributes to a number of environmental problems, such as water quality decline, by emitting pollutants into the natural environment. Agriculture-related processes causing water quality decline include soil erosion, and runoff and percolation of plant nutrients and pesticides. The difficulty in improving water quality is two-fold. Farms are small portions of landscapes embedded in large-scale biophysical and ecological processes at regional scale and therefore farming activities are commonly associated with externalities [1]. This means the resulting costs are either borne by society or downstream water users and therefore not considered by the polluter. Secondly, this type of pollution is diffuse, or of non-point source character, and while individual contributions can be minor their collective impact is often significant and accumulates over time $[2,3]$.

Pollution control policy is largely concerned with the design and performance of emissions-based instruments in situations where pollution sources identified and emissions can be measured accurately $[4,5,6]$. In comparison, there have been limited policy responses to diffuse (or non-point) pollution problems because of two inherent features [6,7]. Firstly, there is a high degree of uncertainty about non-point emissions and current monitoring technology cannot attribute nonpoint emissions to particular emitters with reasonable accuracy and/or at reasonable cost. Secondly, the spatial variation in emission affects feasibility, effectiveness and cost of technical options for reducing emissions. Consequently, the policy focus has been on design-based or indirect instruments, whereby the land use activities are targeted that are thought to cause the pollution $[8,9,10]$. Indirect instruments are considered more likely to provide cost-effective control, particularly when monitoring and enforcement costs are considered.

The policy response to diffuse pollution problems must focus on the actual characteristics of the environmental problem and its spatial variability, and the human factors that constrain improvements [6]. The literature conclusively suggests the adoption of innovations, including conservation practices, by farmers is primarily driven by the extent to which the proposed practices are seen to support their goals, and the perceived riskiness of the innovations e.g. [10].

The objective of this paper is to provide, through an exploratory and descriptive case study, empirical insights into what incentives-and combinations thereof-may be best suited to generating water quality improvements in a river basin located in north-eastern Australia. It provides a contribution to the body of empirical literature as well as helping to support the design of effective and efficient regional programmes and initiatives for the Burdekin River basin.

\section{Background}

The Great Barrier Reef (GBR) is the largest coral reef ecosystem in the world, covering an area of $347,800 \mathrm{~km}^{2}$ and measuring over $2000 \mathrm{~km}$ in length along 


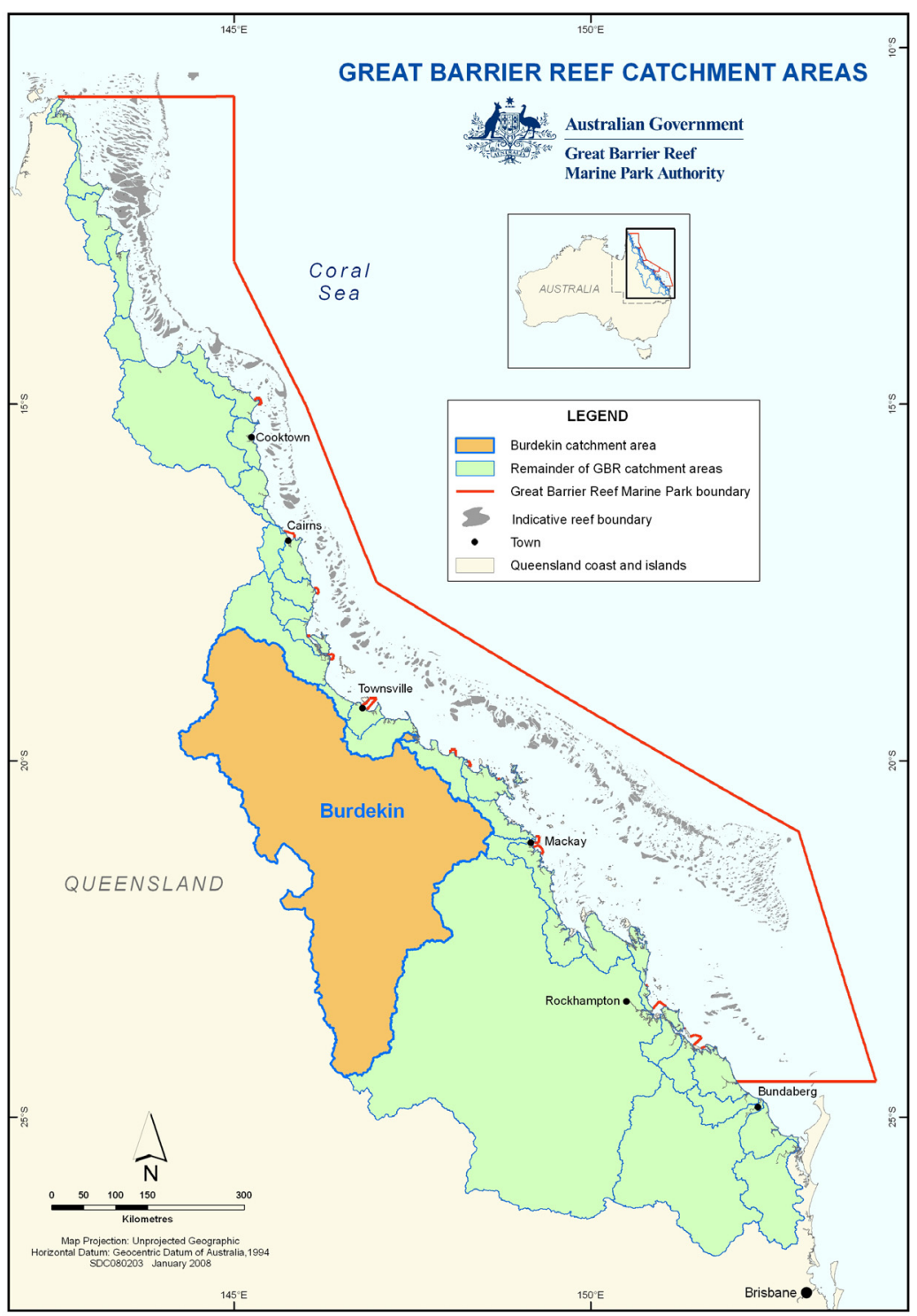

Figure 1: $\quad$ Burdekin River basin in the context of the GBR catchment.

the north-eastern Australian coast, fig. 1. It was designated a World Heritage Area in 1981 in recognition of its outstanding intrinsic values [11]. Its annual contribution to the economy was estimated to be AUD6.1 billion [12]. The health of the Great Barrier Reef ecosystem is critically influenced by the nutrients, sediments and other pollutants discharged into the GBR lagoon from a large number of adjacent river catchments. 
The primary land use in these catchments is cattle grazing across the vast rangelands for beef production, covering approximately $98 \%$ of the area. Grazing practices associated with vegetation clearing and overgrazing are thought to contribute substantially to the sediments that are discharged by rivers into the GBR lagoon $[13,14]$. Among the river basins that form the GBR catchment, the Burdekin River basin is thought to generate the largest sediment due to its large size and landscape features [15], fig. 1.

There are substantive public policy efforts underway to improve the water quality entering the GBR lagoon. Among these initiatives is the Coastal Catchment Initiative (CCI), an Australian Government program that seeks to deliver significant targeted reductions in the discharge of water pollutants to agreed 'hotspots', including the Burdekin River basin [16]. The CCI intends to deliver improvements in water quality through design-based instruments, namely assistance for catchment-based water quality plans and the development of region and industry-specific water quality best management practices (BMPs).

The philosophy of best management practices is to integrate the human dimension into a technical or scientific view of how ecosystems need to be managed' [17]. The grazing land BMPs are framed in the context of ensuring a sustainable and profitable beef industry by managing the landscapes in a manner that maximises water quality and minimises the delivery of nutrients and sediments to aquatic systems [17]. Grazing BMPs are primarily about maintaining grass cover to minimise soil erosion by managing grazing pressure via infrastructure (e.g. fencing) and systematic spelling paddocks.

Research by Greiner et al. [19] demonstrated that the adoption of grazing BMPs was linked graziers' goals, i.e. their predominant motivations in managing their cattle operations. Graziers who tended to score high on conservation and lifestyle goals had higher levels of BMP adoption, which corroborated results from other empirical studies e.g. [19].

Those graziers were found to be intrinsically motivated to implement recommended conservation practices and regarded BMPs as an integral part to risk management. In contrast, graziers who scored highly on economic/financial and social goals were found to be requiring extrinsic incentives to adopt BMPs. The same research found that graziers who regarded BMPs as being part of their property (price) risk management strategy tended to have higher levels of BMP adoption. In addition, adoption of more complex BMPs was correlated to graziers' investments into human capacity and knowledge building [18].

\section{Materials and methods}

The data used for this research originated from a survey of landholders in the Burdekin River catchment, which was conducted in late 2006 to explore social and economic dimensions of the implementation of BMPs within a regional and industry context [20].

The data set offered the opportunity for additional quantitative research into how landholder motivations and related to the preferred incentives for adoption of environmental management practices. This research focuses on the subsample 
of 94 grazier respondents (from a total sample of 114), which is the same subsample explored by Greiner et al. [19]. The research is of an exploratory nature due to the small subsample $(<100)$. Average size of respondents' grazing properties was 34506 hectares, maximum size was almost 230000 hectares.

Basic statistics and multivariate techniques were employed for data analysis and were conducted in STATISTICA (v7.1) [21]. Graphics and tables were generated in Microsoft Excel. The alpha level for testing for statistical significance was set at 0.05 unless stated otherwise.

Principal Component Analysis (PCA) was used to (1) explore a set of variables with a view to identifying the underlying structure and (2) to simplify a large set of variables into a smaller, simpler set of factors for further analysis [22] and has been used in previous studies for similar data and outcome [23, 24]. Factor solutions with different numbers of factors were examined before structures were defined to have the most representative and parsimonious set of factors [25].

Correlation analysis (Pearson's R) was performed to test relationships between variables, which were the factors generated by PCA. Items measured using Likert-type scales were treated as continuous variables and standard parametric statistical procedures were employed [25, 26, 27]. Missing data were dealt with in a pair-wise fashion to maximise the sample.

\section{Results}

Survey respondents were asked to rate how strongly various factors served as impediments, preventing them from implementing more conservation practices. There were 31 impediment items, including financial, skills and knowledge, operational, personal and other constraints. The Likert-type rating scale ranged from $1=$ 'not a constraint' to $10=$ 'fundamental constraint'. The highest rating impediment items were 'initial investment cost', 'too much red tape' and 'not enough time', fig. 2, followed by 'variable climate and drought', 'not enough staff or labour', 'high ongoing costs', 'low return on investment', and 'lack of government incentives'. This suggests that predominantly financial considerations, but also institutional, risk and operational aspects act to constrain the implementation of BMPs.

PCA was employed to reduce the item set to seven impediment factors, which explained $65 \%$ of variance. The factors included: Lack of external support and incentives for implementation; practices not recommended by industry; risk and uncertainty; ill-fit with current operating practices; not enough staff/labour and time; and high cost of implementation.

Correlation analysis between the impediment factors and graziers' goals revealed no relationship between the level of lifestyle/conservation motivation and any impediment factors, tab. 1. In contrast, graziers with higher social motivations tended to be constrained by a lack of support from government/society/industry, perceived lack of fit of BMPs with the current operating system and direct costs associated with implementation. The latter constraints were also prevalent among highly economically/financially motivated 


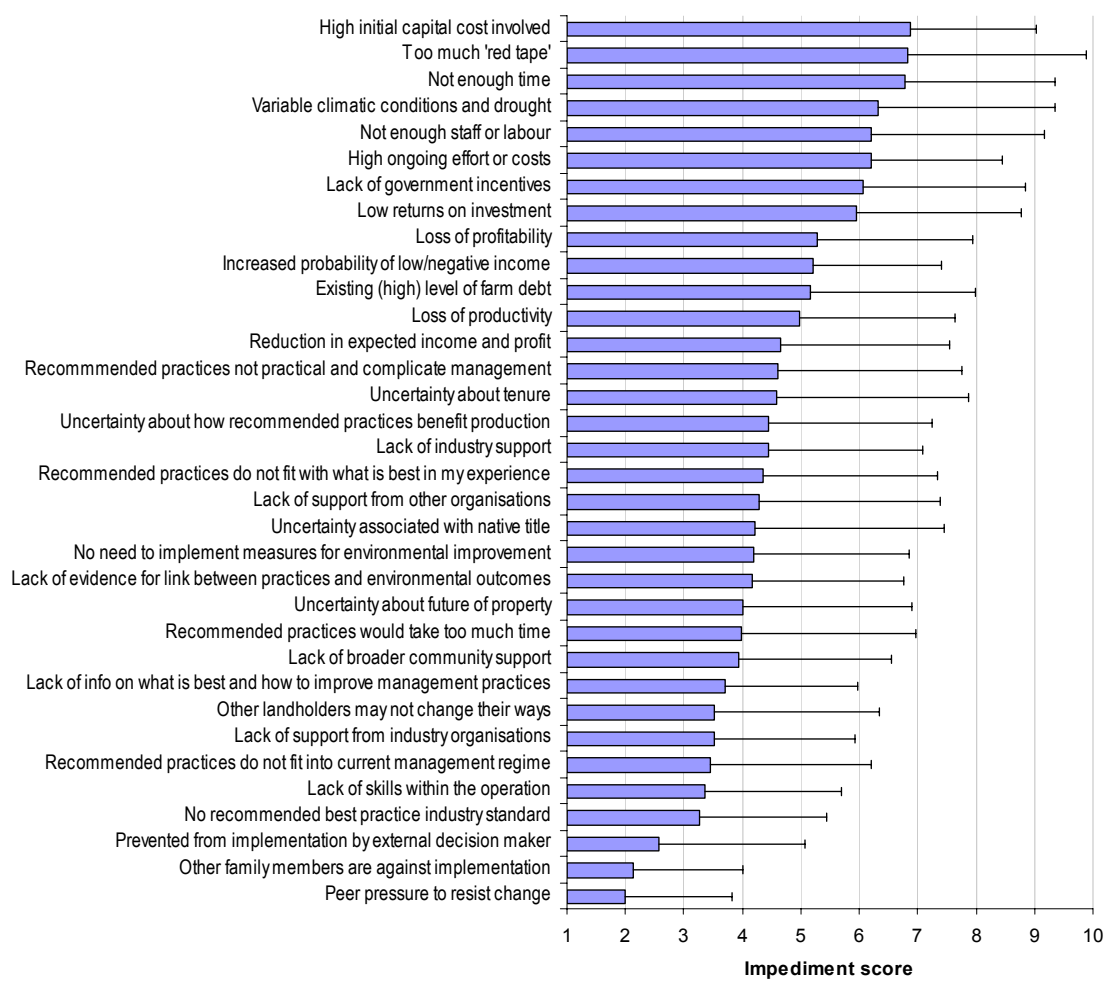

Figure 2: Impediments to the implementation of conservation practices.

Table 1: Correlation matrix between grazier goals and impediment factors.

$$
69<=\mathrm{N}<=81 .
$$

\begin{tabular}{|c|c|c|c|}
\hline \multirow[b]{2}{*}{ Impediment factors } & \multicolumn{3}{|c|}{ Grazier goals } \\
\hline & $\begin{array}{c}\text { Conservation \& } \\
\text { lifestyle }\end{array}$ & $\begin{array}{l}\text { Economic / } \\
\text { financial }\end{array}$ & Social \\
\hline Reduced farm productivity and profitability & -.0190 & .1185 & .1619 \\
\hline Lack of support by government \& industry & .1145 & $.2270^{*}$ & $.2951^{* *}$ \\
\hline BMPs not recommended by peak bodies & .0869 & $.2298^{*}$ & .1168 \\
\hline Risk and uncertainty (climate/markets/etc) & -.0120 & $.2279^{*}$ & .1299 \\
\hline III-fit with current operating system & -.0242 & $.4709^{* * *}$ & $.2727^{* *}$ \\
\hline Not enough time or staff/labour & -.0947 & $.2024^{*}$ & .1404 \\
\hline Direct costs of implementing/doing practices & .1764 & $.4594^{\star * *}$ & $.2835^{\star \star}$ \\
\hline
\end{tabular}

graziers. At the $\mathrm{p}<0.1$ level these graziers also tended to perceive a series of other impediments.

Correlation analysis showed that the more conservation and lifestyle motivated graziers tended to be the ones with lower equity, while no relationship between farm debt or equity and other grazier goals could be established. 
Survey respondents were asked to rate how effective they perceived each of a suite of incentive instruments to be in addressing their impediments to the adoption of conservation practices. The list included 28 incentive instruments from various categories including financial incentives; extension, education and research; regulation; voluntary and industry measures, and recognition incentives. The rating scale ranged from $1=$ 'completely ineffective' to $5=$ 'highly effective'. The mean ratings and standard deviations are shown in fig. 3.

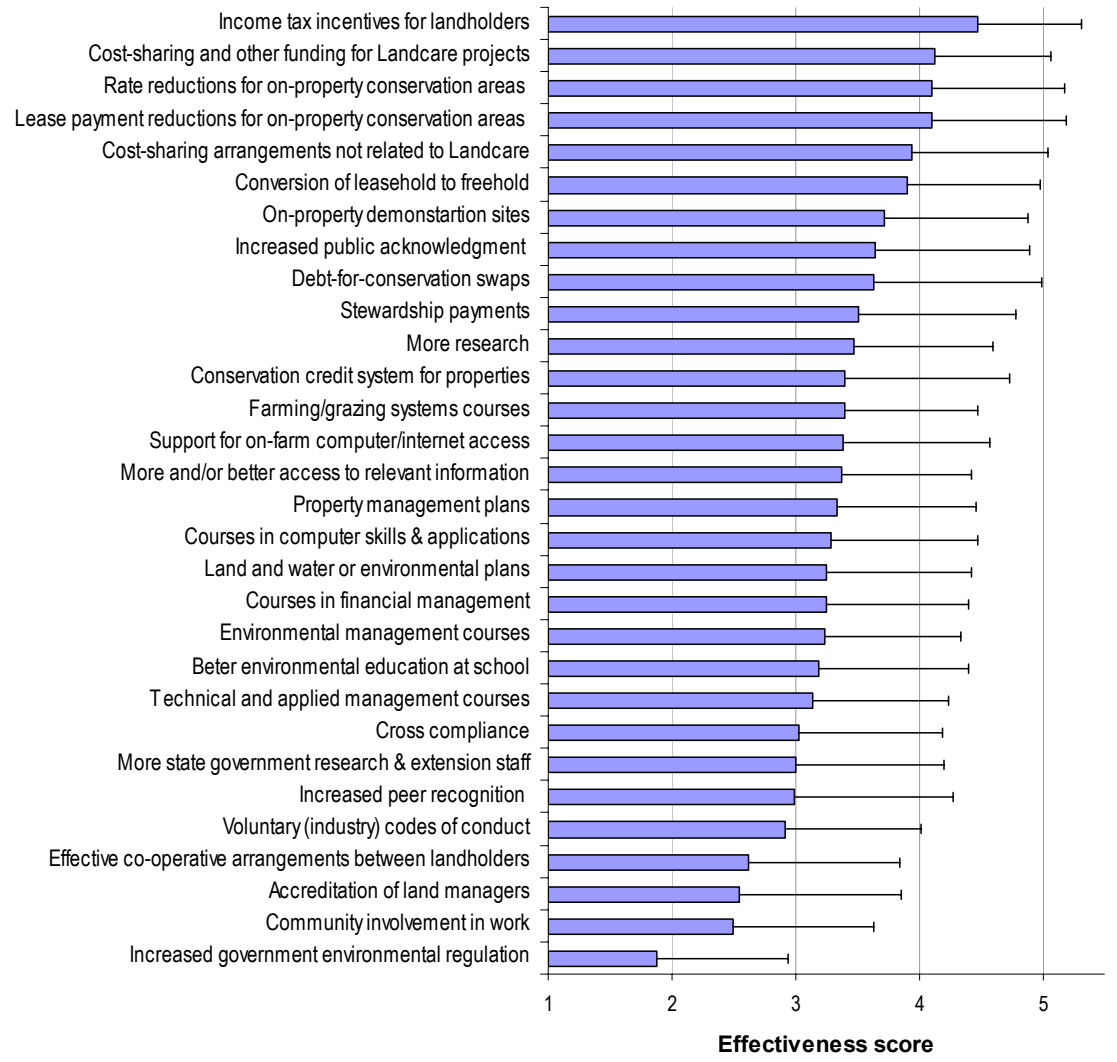

Figure 3: Perceived effectiveness of incentive instruments.

Graziers regarded income tax incentives as the single most effective incentive, followed by a suite of other financial incentives. The prominence given to financial incentives and the overarching desire for tax incentives is consistent with results from an earlier survey by Greiner et al. [29], who noted the strong influence of business advisors and tax agents on farm management decisions across the Burdekin River basin. However, increased security of tenure (conversion of leasehold to freehold), increased public acknowledgement of conservation efforts by landholders, on-property demonstration sites, and more research also received moderate to high effectiveness scores. 
PCA was performed on the incentive items and produced five incentive factors, which explained $>59 \%$ of the variance. The composition of the factors was virtually identical to the conceptual grouping of incentives adopted for the survey [20].

Correlation analysis was conducted between grazier goals and incentive factors, tab. 2. Voluntary and/or industry measures tended to be rated as more effective by more highly motivated graziers, irrespective of the types of goals they pursued. Recognition incentives tended to be rated more highly by graziers with stronger economic/financial and social goals. There were no statistically significant differences detected regarding the perceived effectiveness of financial incentives and regulation/legislation in achieving improved environmental outcomes.

Table 2: $\quad$ Correlation matrix between grazier goals and incentive factors.

$$
66<=\mathrm{N}<=81 .
$$

\begin{tabular}{|l|ccc|}
\hline \multirow{2}{*}{ Incentive factors } & \multicolumn{3}{|c|}{ Grazier goals } \\
\cline { 2 - 4 } & $\begin{array}{c}\text { Conservation \& } \\
\text { lifestyle }\end{array}$ & $\begin{array}{c}\text { Economic / } \\
\text { financial }\end{array}$ & Social \\
\hline Education, extension \& research & $.2138^{\star}$ & $.2124^{*}$ & .0154 \\
Financial incentives & .1617 & .1938 & .1885 \\
Voluntary \& industry meaasures &. $\mathbf{2 6 0 2 ^ { * * }}$ &. $\mathbf{2 4 1 4 ^ { \star * }}$ &. $\mathbf{4 1 7 4}$ \\
Recognition incentives & .1653 &. $\mathbf{3 0 6 9}$ &. $\mathbf{2 4 3 0 ^ { \star * }}$ \\
Regulation & -.0160 & .0532 & .0419 \\
\hline
\end{tabular}

Table 3: Correlation matrix between incentive factors and impediment factors.

$$
65<=\mathrm{N}<=75 .
$$

\begin{tabular}{|c|c|c|c|c|c|}
\hline \multirow[b]{2}{*}{ Impediment factors } & \multicolumn{5}{|c|}{ Incentive factors } \\
\hline & $\begin{array}{l}\text { Education, } \\
\text { extension \& } \\
\text { research }\end{array}$ & $\begin{array}{l}\text { Financial } \\
\text { incentives }\end{array}$ & $\begin{array}{l}\text { Voluntary } \\
\& \text { industry } \\
\text { measures }\end{array}$ & $\begin{array}{l}\text { Recognition } \\
\text { incentives }\end{array}$ & Regulation \\
\hline Reduced farm productivity and profitability & -.0783 & -.0987 & .0699 & .0508 & -.0245 \\
\hline Lack of support by government \& industry & -.0097 & $.2471^{\star *}$ & $.2569^{\star *}$ & .1802 & $.2537^{\star *}$ \\
\hline BMPs not recommended by peak bodies & .1624 & .1403 & $.3223^{\star * *}$ & .0246 & $.2055^{\star}$ \\
\hline Risk and uncertainty (climate/markets/etc) & .0786 & -.0119 & $.4475^{\star \star \star}$ & .1577 & -.1173 \\
\hline III-fit with current operating system & .0357 & .0852 & $.2718^{* *}$ & $.3353^{\star * *}$ & -.0446 \\
\hline Not enough time or staff/labour & -.0813 & -.0205 & .0110 & .0292 & -.0380 \\
\hline Direct costs of implementing/doing practice & .1551 & .1849 & $.2746^{* \star}$ & $.3222^{\star \star *}$ & .0505 \\
\hline
\end{tabular}

Correlation analysis between incentive factors and impediment factors shows that those respondents who tended to rate voluntary and industry measures as highly effective, tended to be constrained by a number of impediments - with the exception of farm profitability and not enough time/staff/labour, tab. 3. Those who tended to rate 'lack of support' more highly as an impediment rated financial incentives, voluntary measures as well as regulation/legislation as being more effective. Recognition incentives were rated highly by those who regarded ill-fit with current operating system and direct cost has major impediments. 


\section{Discussion and conclusions}

The approach, in Australia, to address diffuse water pollution problems in key regions, such as the GBR catchment, by developing region and industry-specific conservation practises in consultation with landholders provides a first step to addressing the discharge of water pollutants from agricultural lands. The approach is consistent with recommended policy approaches to diffuse pollution problems. However, in itself this does not provide a sufficient strategy, as results from this exploratory case study for graziers in the Burdekin River catchment indicate. Rather, a strategic mix of incentives is required to facilitate the broadscale adoption of conservation practices, at the critical extent and rate of change required for discernable improvements in the water quality delivered by the Burdekin River to the GBR lagoon in order to preserve the intrinsic values that underpin its World Heritage status [29].

BMPs have been adopted particularly by those graziers who pursue lifestyle and conservation goals and are intrinsically motivated to adopt conservation practices. However, graziers with high economic/financial and social motivation require external incentives, specifically where changes to the current operating system are comprehensive and risky [30]. They require incentives because they see themselves constrained by particularly financial impediments and perceive a disconnection between conservation practices and industry expectations. Conservation practices need to be endorsed or recommended by industry bodies to penetrate the mainstream grazing community.

The results also suggest that there is quite rightly a focus on financial incentives, which are favoured by all landholders irrespective of their main goals and constraints. While income tax incentives provide a blanket and substantive financial lure, they need to be complemented by region-specific cost sharing programmes designed to overcome the financial barriers of the initial investment and also act as a risk premium. There is already a focus on developing smallscale regional cost sharing programmes with landholders to foster environmental performance across various environmental domains. However, the design of conservation practices as well as financial programmes will be more effective and efficient if they, too, are linked more strongly with and supported by regional industry organisations.

Incentives do not always have to take the shape of financial incentives. An often ignored motivation is recognition. Recognition, by peers and the community, of conservation efforts serves as a powerful incentive for highly motivated graziers. The reverse may also be true, i.e. that a lack of recognition may lead to a decline of the voluntary (and 'free') provision of environmental services by landholders.

Extension, education and research play a critical supporting role in the adoption process. New paradigms and social imperatives require different ways of managing the land, which graziers need to comprehend and be skilled to implement and maintain, while trying to steer their often very large properties through volatile climatic and market conditions. Finally, appropriate regulatory 
intervention is also a key component of an integrated incentives strategy to combat diffuse source water pollution.

\section{Acknowledgements}

The initial survey upon which this paper is based was funded by the Coastal Catchment Initiative and the Burdekin Dry Tropics NRM through funding provided by the National Action Plan for Salinity and Water Quality. The map was provided courtesy of the Spatial Data Centre, Great Barrier Reef Marine Park Authority.

\section{References}

[1] Vatn, A. and Bromley, D.W., Externalities - a market model failure. Environmental and Resource Economics, 9, pp. 135-141, 1997.

[2] Ferrier, R.C., D'Arcy, B.J., MacDonald, J. and Aitken, M., Diffuse pollution - what is the nature of the problem? Journal of the Chartered Institution of Water and Environmental Management, 19(4), pp. 361-366, 2005.

[3] Taylor, M.L., Adams, R.M. and Miller, S.F., Farm-level response to agricultural effluent control strategies: the case of the Willamette valley. Journal of Agricultural and Resource Economics, 17(1), pp. 173-185, 1992.

[4] Shortle, J.S. and Horan, R.D. The economics of nonpoint pollution control. Journal of economic surveys, 15(3), pp. 255-289, 2001.

[5] Russell, C.S. and Powell, P.T., Practical considerations and comparison of instruments of environmental policy. Handbook of environmental and resource economics, ed. J. van den Bergh, Edward Elgar Publishing Inc: Cheltenham UK, 1999.

[6] Falconer, K.E., Managing diffuse environmental contamination from agricultural pesticides: an economic perspective on issues and policy options, with particular reference to Europe. Agriculture, Ecosystems and Environment, 69, pp. 37-54, 1998.

[7] Shortle, J.S., Horan, R.D. and Abler, D.G., Research issues in nonpoint pollution control. Environmental and Resource Economics, 11(3-4), 571$585,1998$.

[8] Helfand, G.E. and House, B.W., Regulating nonpoint source pollution under heterogeneous conditions. American journal of Agricultural Economics, 77, pp. 1024-1032, 1995.

[9] Ribaudo, M. O., Heimlich, R., Claassen, R. and Peters, M., Least-cost management of nonpoint source pollution: source reduction versus interception strategies for controlling nitrogen loss in the Mississippi Basin. Ecological Economics, 37, 183-197, 2001.

[10] Pannell, D.J., Marshall, G.R., Barr, N., Curtis, A., Vanclay, F., and Wilkinson, R., Understanding and promoting adoption of conservation 
technologies by rural landholders. Australian Journal of Experimental Agriculture, 46, 1407-1424, 2006.

[11] $\mathrm{Wu}$, J. and Babcock, B.A., Spatial heterogeneity and the choice of instruments to control nonpoint pollution. Environmental and resource economics, 18, pp. 173-192, 2001.

[12] Lucas, P.H.C., Webb, T., Valentine, P.S. and Marsh, H., The outstanding universal value of the Great Barrier Reef World Heritage Area. Great Barrier Reef Marine Park Authority, 1997.

[13] Access Economics, Measuring the economic and financial value of the Great Barrier Reef Marine Park. Great Barrier Reef Marine Park Authority: Canberra, 2005.

[14] Brodie, J.E., McKergow, L.A., Prosser, I.P., Fumas, M., Hughes, A.O. and Hunter, H., Sources of sediment and nutrient exports to the Great Barrier Reef World Heritage Area (ACTFR Report No. 03/11). Australian Centre for Tropical Freshwater Research, James Cook University: Townsville, 2003.

[15] Fumas, M., Catchments and Corals: Terrestrial Runoff to the Great Barrier Reef. Australian Institute of Marine Science and CRC Reef Research Centre: Townsville, 2003.

[16] Roth, C.H., Lawson, G. and Cavanagh, D., Overview of key natural resource management issues in the Burdekin catchment: with particular reference to water quality and salinity (Burdekin condition study phase 1). Burdekin Dry Tropics Board: Townsville, 2002.

[17] The Australian Government, http://www.environment.gov.au/coasts/ pollution/cci/index.html

[18] Coughlin, T., O'Reagain, P. and Nelson, B., Draft review of current and proposed grazing land best management practices for achieving water quality objectives in the Burdekin catchment (Grazing land management for Burdekin water quality outcomes). ACTFR, James Cook University: Townsville, 2006.

[19] Greiner, R., Miller, O. and Patterson, L., The role of grazier motivation and risk attitudes in the adoption of grazing best management practices. Proc. of the $52^{\text {nd }}$ Annual Conference of the Australian Agricultural and Resource Economics Society, 2008.

[20] Chouinard, H.H., Paterson, T., Wandschneider, P.R., and Ohler, A.M., Will Farmers Trade Profits for Stewardship? Heterogeneous Motivations for Farm Practice Selection. School of Economic Sciences, Washington State University, 2006.

[21] Greiner, R., Lankester, A. and Patterson, L., Incentives to enhance the adoption of Best Management Practices by landholders: Achieving water quality improvements in the Burdekin River Catchment (Report to the Burdekin Dry Tropics NRM and Coastal Catchment). River Consulting: Townsville, 2007.

[22] Statsoft, STATISTICA System Reference. StatSoft: Tulsa, 2001.

[23] Diekhoog, G., Statistics for the Social and behavioural Sciences: Univariate, Bivariate, Multivariate, Wm. C. Brown Publishers: IA, 1992. 
[24] Flaten, O., Lien, G., Koesling, M., Valle, P.S. and Ebbesvik, M., Comparing risk perceptions and risk management in organic and conventional dairy farming: empirical results from Norway. Livestock Production Science, 95(1-2), pp. 11-25, 2005.

[25] Maybery, D., Crase, L. and Gullifer, C., Categorising farming values as economic, conservation and lifestyle. Journal of Economic Psychology, 26(1), pp. 59-72, 2005.

[26] Lien, G., Hardaker, B.J. and Flaten, O., Risk and economic sustainability of crop farming systems. Agricultural Systems, 94 (2), pp. 541-552, 2007.

[27] Meuwissen, M.P.M., Huirne, R.B.M. and Hardaker, J.B., Risk and risk management: an empirical analysis of Dutch livestock farmers. Livestock Production Science, 69(1), pp. 43-53, 2001.

[28] Patrick, G.F. and Musser, W.N., Sources of and responses to risk: factor analysis of large-scale US cornbelt farmers. Risk management strategies in agriculture (Volume 7), eds. R.B.M. Huirne, J.B. Hardaker, and A.A. Dijkhuizen, Wageningen Agricultural University: Wageningen, 1997.

[29] Greiner, R., Stoeckl, N., Stokes, C., Herr, A., and Bachmaier, J., Natural resource management in the Burdekin Dry Tropics: social and economic issues (Report for the Burdekin Dry Tropics NRM Board) River Consulting: Townsville, 2003.

[30] Novotny, V., Water quality (2 ${ }^{\text {nd }}$ edition): Diffuse pollution \& watershed management, John Wiley and Sons: New York, 2003.

[31] De Buck, A.J., van Rijn, I., Roling, N.G. and Wossink, G.A.A., Farmers' reasons for changing or not changing to more sustainable practices: an exploratory study of arable farming in the Netherlands. The journal of Agricultural Education and Extension, 7(3), pp. 153-166, 2001. 